Received: 25 October 2016

Accepted: 19 October 2017

Published online: 20 November 2017

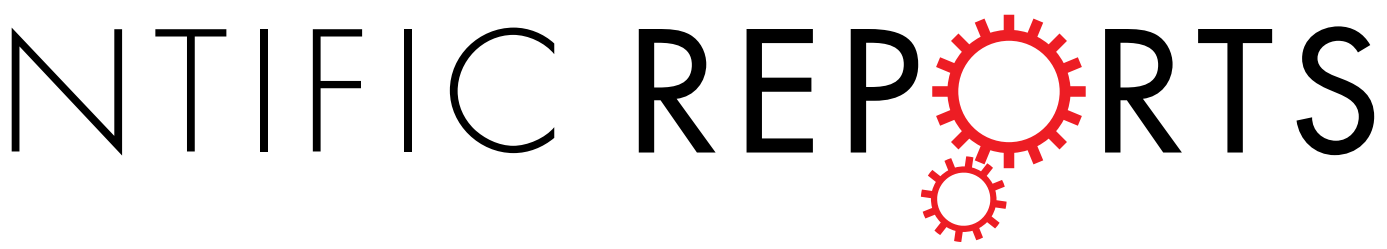

\title{
Expression of SRY-related HMG Box Transcription Factors (Sox) 2 and 9 in Craniopharyngioma Subtypes and Surrounding Brain Tissue
}

Vivian Thimsen ${ }^{1}$, Nora John ${ }^{1}$, Michael Buchfelder ${ }^{2}$, Jörg Flitsch ${ }^{3}$, Rudolf Fahlbusch ${ }^{4}$, Harald Stefanits ${ }^{5}$, Engelbert Knosp ${ }^{5}$, Marco Losa ${ }^{6}$, Rolf Buslei $\mathbb{B}^{7}$ \& Annett Hölsken ${ }^{1}$

Stem cells have been discovered as key players in the genesis of different neoplasms including craniopharyngioma (CP), a rare tumour entity in the sellar region. Sox2 and Sox9 are well-known stem cell markers involved in pituitary development. In this study we analysed the expression of both transcription factors using immunohistochemistry in a large cohort of 64 adamantinomatous (aCP) and 9 papillary $C P(p C P)$ and quantitative $P C R$ in 26 aCP and $7 p C P$. Whereas immunohistochemically Sox $2+$ cells were verifiable in only five aCP $(7.8 \%)$ and in $39.1 \%$ of the respective surrounding cerebral tissue, pCP specimens appeared always negative. In contrast, Sox9 was detectable in all tumours with a significantly higher expression in aCP compared to $\mathrm{pCP}$ (protein, $p<0.0001$; mRNA $p=0.0484$ ) This was also true for the respective tumour adjacent CNS where $63 \mathrm{aCP}(98.4 \%)$ and six PCP (66.7\%) showed Sox $9+$ cells. We further confirmed absence of Sox 9 expression in nuclear $\beta$-catenin accumulating cells of aCP. Our results point to the conclusion that Sox 2 and Sox9, seem to play essential roles not only in the specific formation of aCP, but also in processes involving the cerebral tumour environment, which needs to be illuminated in the future.

The sellar region represents an important interface of the human brain with close proximity to essential vascular and neural structures. It is at this precise and critical location that craniopharyngioma (CP), a group of rare intracranial epithelial tumours, occur. Although these neoplasms are designated as histologically benign (WHO-grade I) tumours ${ }^{1}$, their immediate proximity to crucial anatomical brain structures like the hypothalamus, the pituitary stalk, the cavernous sinus and the optic chiasm, makes them a major clinical and surgical challenge causing serious sequelae $\mathrm{e}^{2,3}$. CP, which represent $2-5 \%$ of all primary intracranial neoplasms, can be divided in two subtypes, adamantinomatous (aCP) and papillary (pCP) CP, which differ in terms of histological, clinical, and genetic issues ${ }^{4,5}$. ACP, with their characteristic of nuclear $\beta$-catenin accumulating cell clusters ${ }^{6-9}$, represent the more frequent variant, occurring mainly during childhood and showing a higher rate of loco-regional recurrences ${ }^{10}$.

In contrast, pCP are almost exclusively found in adults and show a milder progression of disease ${ }^{3}$. Although the precise origin of $\mathrm{CP}$ still remains unknown up to this point, aCP are thought to derive from pituitary progenitor/stem cells representing embryonal remnants of Rathke's pouch epithelium, whereas pCP are hypothesized to represent metaplasia of squamous epithelia ${ }^{11,12}$. The assumption that so-called cancer stem cells (CSC) are involved in CP-formation has also gained in importance in the last years ${ }^{13}$. CSC are thought to share many features of dormant stem cells. They have the ability to force self-renewal and differentiation, but are lacking balance in cell divisions a situation caused by the accumulation of genetic events ${ }^{14-16}$. One of the most well-known dysregulations are activating mutations in components of the Wnt-signalling pathway ${ }^{17}$. Mutations in CTNNB1,

${ }^{1}$ Department of Neuropathology, Friedrich-Alexander University Erlangen-Nürnberg (FAU), Erlangen, Germany. ${ }^{2}$ Department of Neurosurgery, Friedrich-Alexander University Erlangen-Nürnberg (FAU), Erlangen, Germany. ${ }^{3}$ Department of Neurosurgery, University Clinic Hamburg-Eppendorf, Hamburg, Germany. ${ }^{4}$ Department of Neurosurgery, International Neuroscience Institute, Hannover, Germany. ${ }^{5}$ Department of Neurosurgery, Medical University of Vienna, Vienna, Austria. ${ }^{6}$ Ospedale San Raffaele, Department of Neurosurgery, Milano, Italy. ${ }^{7}$ Department of Pathology, Sozialstiftung Bamberg, Bamberg, Germany. Correspondence and requests for materials should be addressed to R.B. (email: rolf.buslei@sozialstiftung-bamberg.de) 
the gene encoding $\beta$-catenin, have been described in the vast majority of aCP samples ${ }^{6,8}$, and increased Wingless (Wnt) signalling in pituitary progenitor/stem cells in mice gives rise to pituitary tumours resembling aCP $\mathrm{P}^{12}$. Furthermore, the expression of several markers of stemness, like OCT-4, KLF4, CD44 and CD133 (Prominin 1), has previously been described in aCP cell clusters showing nuclear $\beta$-catenin accumulations ${ }^{18,19}$.

Members of the Sry-related HMG (high mobility group) box (Sox) transcription factors are additional markers of stemness. 20 different factors, all divided into 9 subgroups $(\mathrm{A}-\mathrm{H} \text {, with } \mathrm{B} 1 \text { and } \mathrm{B} 2)^{20-22}$ have been identified to date. Sox2 (SoxB1 group) is widely expressed in developing CNS and is essential for the development of the hypothalamic-pituitary axis, showing a uniform expression pattern in Rathke's pouch ${ }^{23-25}$. Sox 2 amplification has further been described in relation to different types of cancer ${ }^{26-28}$. Sox $2+$ stem/progenitor cells in the adult mouse pituitary further evinced tumour-inducing potential in a non-cell-autonomous manner ${ }^{29,30}$. Sox9 (SoxE group) plays various important roles in the development of cartilage ${ }^{31-33}$, sex organs $s^{34}$, and the $\mathrm{CNS}^{35}$. It has been described to be essential for the induction and maintenance of neural stem cells ${ }^{36}$ and also for the further promotion of the neuron-glia switch in the spinal cord ${ }^{37}$. To this date different studies about expression and role of Sox 2 and Sox9 in CP development and maintenance exist but are based on only small numbers of tumour samples and information regarding the papillary subtype is rare ${ }^{12,19,29,38,39}$. However, data about the expression of Sox 2 and Sox9 in the tumour surrounding brain tissue is lacking. In order to obtain detailed information about the expression of the stem cell factors in both human CP subtypes, we specifically investigated the immunohistochemical distribution pattern in a large cohort of tumour samples in association to the adjacent brain tissue and furthermore their gene expression using quantitative PCR. As several interactions of Sox 2 and Sox 9 with $\beta$-catenin, a member of the Wnt signalling pathway, were already described, we carefully examined the distribution pattern of these proteins $s^{33,40,41}$. In addition, we also investigated the co-expression of Sox 2 and Sox 9 with the oligodendrocyte transcription factor 2 (Olig2) as well as the glial fibrillary acid protein (GFAP) to define tumour surrounding cerebral microenvironment. Olig2 is known for determining oligodendrocyte differentiation, is expressed in glial precursor cells, and is also described to be involved in the formation of brain tumours, especially gliomas ${ }^{42}$.

\section{Results}

Very Low Expression of Sox2 in CP Subtypes Compared to the Tumour Surrounding Cerebral

Tissue. We examined the distribution pattern of Sox 2 in a cohort of $64 \mathrm{aCP}$ and $9 \mathrm{pCP}$ using immunohistochemistry. As part of our investigation, we considered the protein expression in both the tumour tissue as well as in the tumour adjacent brain parenchyma. When assessing the pCP specimens, we were unable to find any specific positive nuclear antigen reaction for Sox 2 at all. In the group of aCP, a nuclear staining for Sox 2 within the tumour tissue was hardly detectable as well. Only five cases (7.8\%) revealed a few interspersed cells showing slight Sox 2 expression (Fig. 1a,b,c). These cells were not only restricted to the cords, trabeculae and lobules of well-differentiated epithelium, but were also detectable in the palisading cell layer (Fig. 1b). However, the Sox $2+$ cells were obviously not localised within nodular whorls as was described for aCP reminiscent tumours in mouse models ${ }^{29}$. In contrast, we were able to prove a certain immunoreactivity in cells of the tumour surrounding brain tissue in 25 of the aCP samples (39.1\%), as presented in Fig. 1(b,c,d). Double immunohistochemistry using the glial marker GFAP affirms that the occurrence of Sox 2 + cells was restricted to occasional regions in the immediate vicinity of the tumour border where they often seemed to accumulate in certain areas of the cerebral microenvironment without showing a widespread distribution among the more distant brain parenchyma. Furthermore, it is remarkable that staining intensity of these Sox $2+$ cells was clearly higher than within the tumour tissue (Fig. 1b,c) The distribution pattern of Sox $2+$ cells is summarised and illustrated in Fig. 6a,b. Comparing the relative gene expression of Sox 2 in aCP $(n=26$; Median $=1.136)$ an $\mathrm{pCP}(\mathrm{n}=7$; Median $=2.114)$ using quantitative $\mathrm{PCR}$, the mRNA levels were almost equally distributed among aCP and $\mathrm{pCP}$ without any significant differences (S-Fig. 2a) [Mann-Whitney-test: $\alpha \leq 0.05 ; p=0.3295]$.

Sox9 was Significantly Expressed in Both CP Subtypes and the Tumour Surrounding Brain Tissue. We also examined the distribution pattern of Sox9 in the same cohort of CP samples. As the tumours showed significantly higher amounts of protein expression overall, we defined a semi-quantitative total immunostaining score (TIS) for each case as described in detail in the methods section of this manuscript. Based on the calculated TIS, all specimens were subsequently divided into three different scoring groups (S1: TIS $<0$; S2: TIS $=1-4$; S3: TIS $>4$ ). Although Sox9 staining was detectable in each tumour, there was, however, an obviously stronger antibody reaction perceptible in aCP compared to pCP. This observation was also reflected in the distribution of the scoring groups among both tumour subtypes, pointing to a significantly higher Sox9 expression in aCP [Fisher's exact test (two-sided): $p<0.0001$ ]. Whereas $p C P$ showed only low to moderate Sox9 immunostaining levels (S2) in general, the majority (51 specimens; 79.7\%) of aCP specimens revealed a strong staining pattern (S3). Examples demonstrating the varying strength of Sox9 immunoreactivity in both CP subtypes are shown in Fig. $2 \mathrm{a}-\mathrm{d}$. The respective scoring groups are illustrated in Fig. 2e. Even comparing the results from quantitative real time PCR, we could proof a significantly higher Sox9 mRNA expression rate in aCP $(\mathrm{n}=26$, Median $=8,98)$ compared to $\mathrm{pCP}(\mathrm{n}=7$, Median $=1,728)$, (Fig. 2f) [Mann-Whitney-test (two-sided): $\alpha \leq 0.05 ; p=0.0484$ ]. Comparing Sox 2 and Sox 9 expression in aCP, staining intensity implicate enhanced Sox9 levels which is also confirmed by mRNA expression levels (S-Fig. 2a). Sox9 mRNA expression levels of aCP in relation to Sox2 expression levels $(n=26$, Median $=1.136)$ were significantly lower than Sox9 values $(n=26$, Median $=8.98$, Mann-Whitney-test (two-sided): $p<0.0001$ ).

In addition to Sox9+ tumour cells, we were also able to detect a strong nuclear Sox9 signal in several cells within the tumour surrounding GFAP + cerebral tissue, both in aCP ( $98.4 \%$ of the patient samples) and pCP specimens ( $66.7 \%$ of the tumours). Once again, the average quantity and staining intensity was higher in the group of aCP samples when compared to pCP. The detailed scoring results for each tumour specimen are given in S-Table 1 and S-Fig. 1. It was evident that the amount and the intensity of positive cells in the tumour surrounding brain 

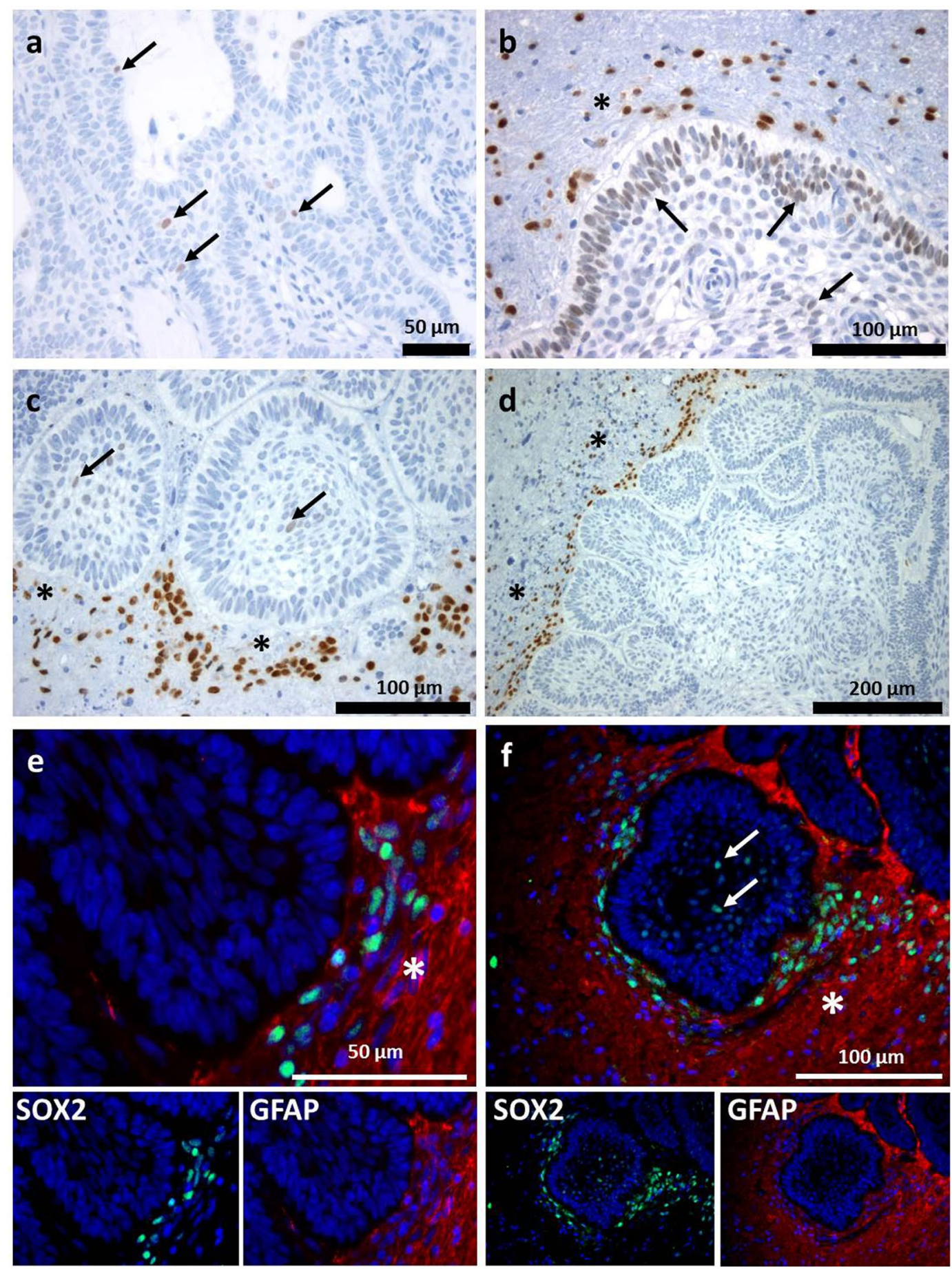

Figure 1. Immunohistochemical Expression Pattern of Sox 2 in aCP and Surrounding Brain Tissue. (a-c) Nuclear Sox 2 staining (arrow) was found within aCP tumour bulk and palisading cell layer and in cells of the tumour surrounding brain tissue (asterisk; b,c,d). (e,f) Merged double-immunofluorescence staining of Sox2 (green) and the glial marker GFAP (red) demarcating adjacent brain tissue (asterisk) of the tumour revealed Sox $2+$ cells being enhanced nearby the CNS-tumour junction. (f) The GFAP negative tumour tissue showed also Sox $2+$ cells (arrow). $($ ada27 $=a$, ada $56=b$, ada $48=c, d, e ;$ ada50 $=$ f).

tissue did not correlate with the extent of Sox 9 expression in the respective tumour tissue. Examples of the various combinations found in aCP are presented in Fig. 3a-d. Interestingly, we were able to find a significant association between high amounts of Sox9+ cells $(>50 \%$; BT3; $n=17)$ and the occurrence of Sox $2+$ cells $(n=12)$ in the aCP surrounding brain tissue $[\mathrm{n}($ Sox $2-)=39 ; \mathrm{n}(\operatorname{Sox} 2+)=23$; Fisher's exact test (two-sided): $p=0.0013]$. The CP subtype specific distribution pattern of Sox 2 and Sox9 positive cells is summarised and illustrated in Fig. 6a-d.

To gain more information about the properties of Sox $2+$ and Sox9+ cells located near the aCP, we decided to perform double-immunofluorescence staining of selected tumour samples using antibodies against Sox 2 or Sox 9 
and Olig2. By doing so, we could prove a distinct co-expression of both proteins in several, but not all of the cells (Fig. 4). GFAP double immunohistochemistry was performed exemplary with Sox2 and Sox9 antibody to illustrate demarcation of the brain tissue (GFAP+) from tumour tissue (GFAP-) (Figs 1e,f; 3e; 4).

Divergent Expression Patterns of Sox 9 and $\beta$-catenin in aCP. During the analysis of the aCP samples, it became apparent that not all cells within the tumour bulk revealed nuclear staining for Sox9. Especially whirl-like cell clusters, typically showing nuclear $\beta$-catenin accumulations, completely lacked Sox 9 expression, regardless of the case. In contrast, adjoining cells were characterised by a strong nuclear expression of the transcription factor, as documented in serial sections (Fig. 5a,b) and in double-immunofluorescence staining (Fig. 5c). Tumour cells of the palisading basal cell layer, bordering on adjacent brain tissue, revealed strong nuclear staining in most of the tumour samples as well (Fig. 5a,c). The distribution pattern of Sox $9+$ cells is summarised and illustrated in Fig. 6c,d.

Association of Sox 2 and Sox 9 Expression and Clinicopathological Features. To address a potential prognostic value of Sox 2 and Sox 9 expression for patient care, we compared our results for gene expression (S-Fig. 2), and in case of Sox9 additionally the calculated staining scores, with several clinicopathological characteristics like age group, gender, and invasiveness. For none of those features a level of significance $(p<0,05)$ could be reached: Neither matching with relative gene expression results [gender: $\mathrm{n}($ male $)=16 ; \mathrm{n}($ female $)=10$; Mann-Whitney-test (two-sided): Sox2 $p=0.8971$; Sox9 $p=0.1089$, S-Fig. 2b; invasiveness: $\mathrm{n}$ (invasive) $=11$; $\mathrm{n}$ (non-invasive) $=11$; Mann-Whitney-test (two-sided): Sox2 $p=0.5190$; Sox9 $p=0.5190$, S-Fig. 2c; age group: $\mathrm{n}($ adult $)=17 ; \mathrm{n}$ (children) =9; Mann-Whitney-test (two-sided): Sox $2 p=0.4580$, Sox9 $p=0.7916$, S-Fig. $2 \mathrm{~d}$ ], nor with Sox9 staining scores [age group: $\mathrm{n}($ adult; age $\geq 19)=41 ; \mathrm{n}$ (children) $=23$; Fisher's exact test (two-sided): $p=1.000$; gender: $\mathrm{n}($ female $)=25 ; \mathrm{n}($ male $)=39$; Fisher's exact test (two-sided): $p=0.1091$; invasiveness: $\mathrm{n}$ (invasive $)=19 ; \mathrm{n}($ non-invasive $)=23$; Fisher's exact test (two-sided): $p=1.000]$. As the available clinical data concerning recurrence among our patient cohort was not extensive enough, we were unable to draw a reliable conclusion.

\section{Discussion}

With rising insights in regulatory cell mechanisms, it has become clear that stem cells, pluripotency and developmental processes are not limited to the embryonic phase, but also that these play critical roles in tissue regeneration and tumour formation in mature tissues ${ }^{43}$. For this reason, the investigation of stem cell markers among neoplasms has increased over the course of the last few years. Sox 2 and Sox 9 are known as crucial transcription factors playing important roles in a great variety of different steps of embryo- and organogenesis and, in particular, in the development of the CNS and the hypothalamic-pituitary axis ${ }^{36,44,45}$. Both proteins have previously been described as being expressed in murine and human CP. As the presented results are based on just a small number of studies and tumour samples and provide no information about the expression of Sox 2 and Sox9 in the tumour surrounding brain tissue ${ }^{19,29,46}$, we investigated the expression of Sox 2 and Sox 9 in a large cohort of aCP and pCP using immunohistochemistry $(64 \mathrm{aCP}, 9 \mathrm{pCP})$, double-immunofluorescence staining and quantitative PCR (26 $\mathrm{aCP}, 7 \mathrm{pCP}$ ). The immunohistochemical distribution pattern was analysed in detail in relation to $\beta$-catenin accumulating cell clusters and the tumour adjacent CNS tissue.

Sox2 represents an universal marker for multipotent neural stem cells both during embryogenesis and in adulthood ${ }^{47}$. The protein has been described as being involved in the pathogenesis of glial neoplasms ${ }^{28}$ as well as epithelial and mesenchymal tumours ${ }^{26}$. Its well-known role in the development of the hypothalamic-pituitary axis is reflected by a homogeneous expression in Rathke's pouch epithelium ${ }^{23-25}$ and makes Sox 2 a potential key player in the development of CP. This hypothesis was backed by the fact that targeted expression of oncogenic $\beta$-catenin in Sox $2+$ stem/progenitor cells in adult mouse pituitaries gives rise to tumours resembling human $\mathrm{CP}^{46}$. In these mice, scattered Sox $2+$ cells were described within small $\beta$-catenin accumulating cell clusters representing a histomorphological hallmark of human aCP, but the expression was seen only temporarily ${ }^{12,46}$. Our data revealed, the rare Sox $2+$ cells found in five tumour samples were not located in or next to $\beta$-catenin accumulating cell clusters, confirming the results presented by Gaston-Massuet and colleagues ${ }^{12}$. They already suggested from the ACP mouse model that Sox $2+$ cells and the cell clusters showing nuclear $\beta$-catenin accumulations might be ontogenetically equal, but that these represent different stages of development ${ }^{46}$. Proving this thesis was not the focus of our investigation, but our results do not contradict this theory. Although, we were able to confirm identified Sox 2 staining pattern in palisading cells and the tumour bulk, as described by Garcia-Lavandeira et al. our study dissent with observations describing the existence of individual Sox $2+$ cells in a high percentage $(12 / 15 ; 80 \%)$ of CP specimens ${ }^{19}$. Therefore, we were hardly able to prove Sox $2+$ cells within the tumour tissue at all. Only few aCP cases $(7.8 \%)$ and absolutely none of the pCP revealed antigen reaction. Interestingly, levels of Sox 2 mRNA expression did not correlate with protein expression. As listed in S-Table 1 cases with Sox 2 expression within the tumour exhibit mostly low mRNA levels, whereas others having high Sox 2 mRNA levels were immunohistochemically negative (e.g. aCP6, aCP8). This discrepancy of mRNA and protein expression could be caused by several reasons like posttranscriptional mechanisms as earlier described ${ }^{48}$. A technical issue cannot be discarded since the Sox 2 antibody used in our work is monoclonal rabbit anti-Sox 2 antibody, while the Sox 9 antibody is a polyclonal rabbit anti-Sox 9 antibody. It is known that monoclonal antibodies are affected by protein posttranslational modifications.

However, the fact that we found Sox $2+$ cells in more than one-third of the tumours surrounding brain tissue may point to the recently suggested non-cell-autonomous role of Sox $2+$ stem/progenitor cells as observed in murine pituitary tumour formation ${ }^{46}$. These cells were predominantly located in the aforementioned tumour-specific cerebral microenvironment of $\mathrm{aCP}^{49}$ and often seemed to accumulate at certain tumour edges. 


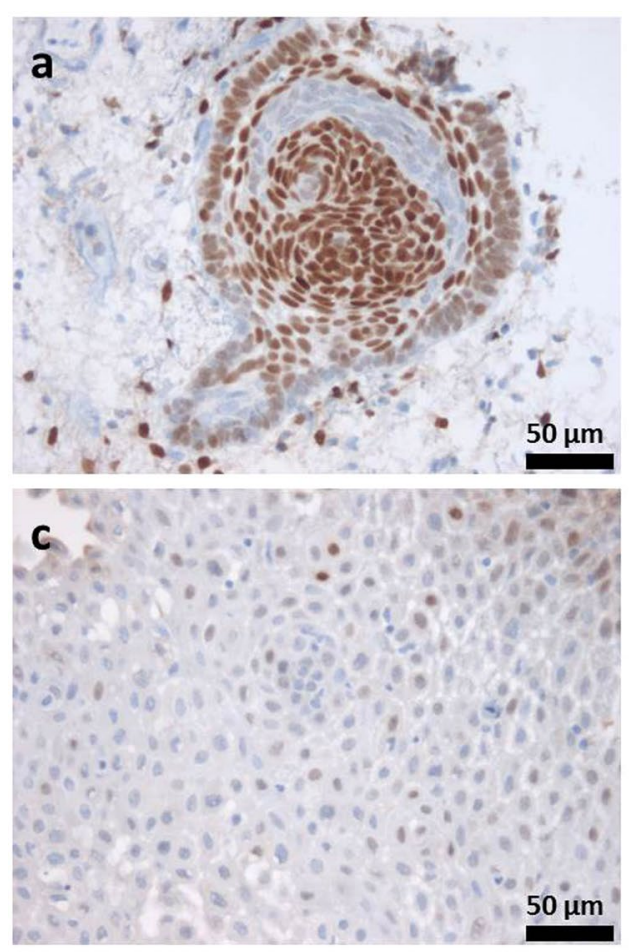

e

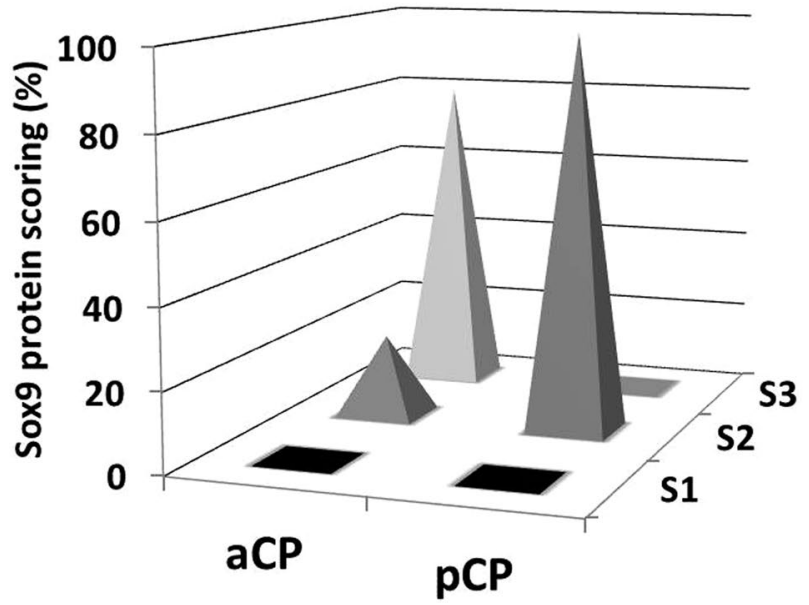

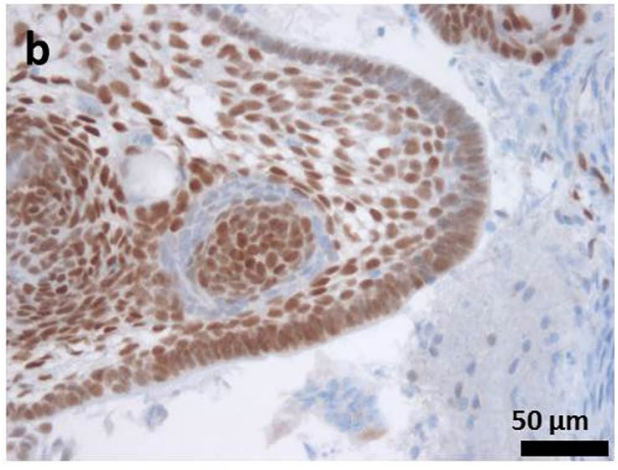

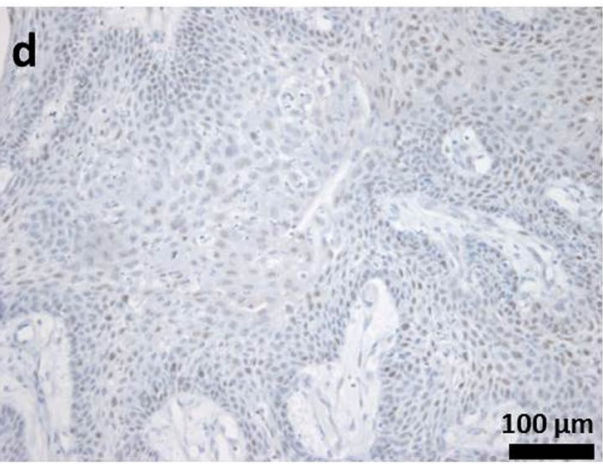

f

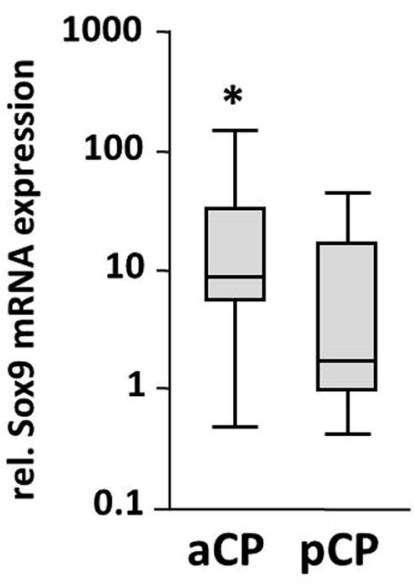

Figure 2. Immunohistochemical Staining of Sox9 in CP Subtypes and Summary of Calculated Sox9 Staining Scores. (a,b) Sox 9 expression in aCP was not evenly distributed throughout the tumour, but rather showed significant regional differences (ada57). Although large proportions of the cells demonstrated a distinct nuclear staining pattern, small cell clusters in the direct vicinity were clearly negative. (c,d) Homogeneous and moderate immunohistochemical staining pattern of Sox9 in pCP (pap3, pap5). (e) The spikes illustrate the percentage shares of the immunohistochemical scoring groups ( 1 1 = "no expression"; S2 = "low/moderate expression"; S3 = "strong expression") within aCP and pCP specimens studied. Nuclear Sox9 staining was found in each of the 73 CP samples. Whereas all pCP samples showed only a moderate Sox9 expression (100\% in group S2), aCP revealed expression in varying intensities (20.3\% in group S2 and $79.7 \%$ in group S3) with a significantly higher overall Sox9 expression in this subtype [Fisher's exact test (two-sided): $p<0.0001$ ]. Exact values for each tumour sample were given in S-Table 1. (f) Sox9 mRNA expression analysis confirmed significantly enhanced levels in $\mathrm{aCP}(\mathrm{n}=26$; mean $=24,47$ in relation to $\mathrm{pCP}(\mathrm{n}=7$; mean $=10,18$; Mann-Whitney test, $\mathrm{p}=0,0484)$.

We speculate that these areas are the biologically active parts of the lesion, inducing tumour outgrowth and causing subsequent hypoxia and injury to the surrounding brain tissue.

As Sox 2 has not only been described to be involved in tumour formation itself but also in damage-induced reactions of the CNS, like reactive processes evoked by non-neuroepithelial CNS tumours ${ }^{50}$ and penetrating stab wounds ${ }^{51,52}$, we also examined the expression of Sox 2 in relation to the CNS tissue markers GFAP and Olig2. GFAP is a main component of the cytoskeleton of glial cells, especially astrocytes and was used to define tumour 

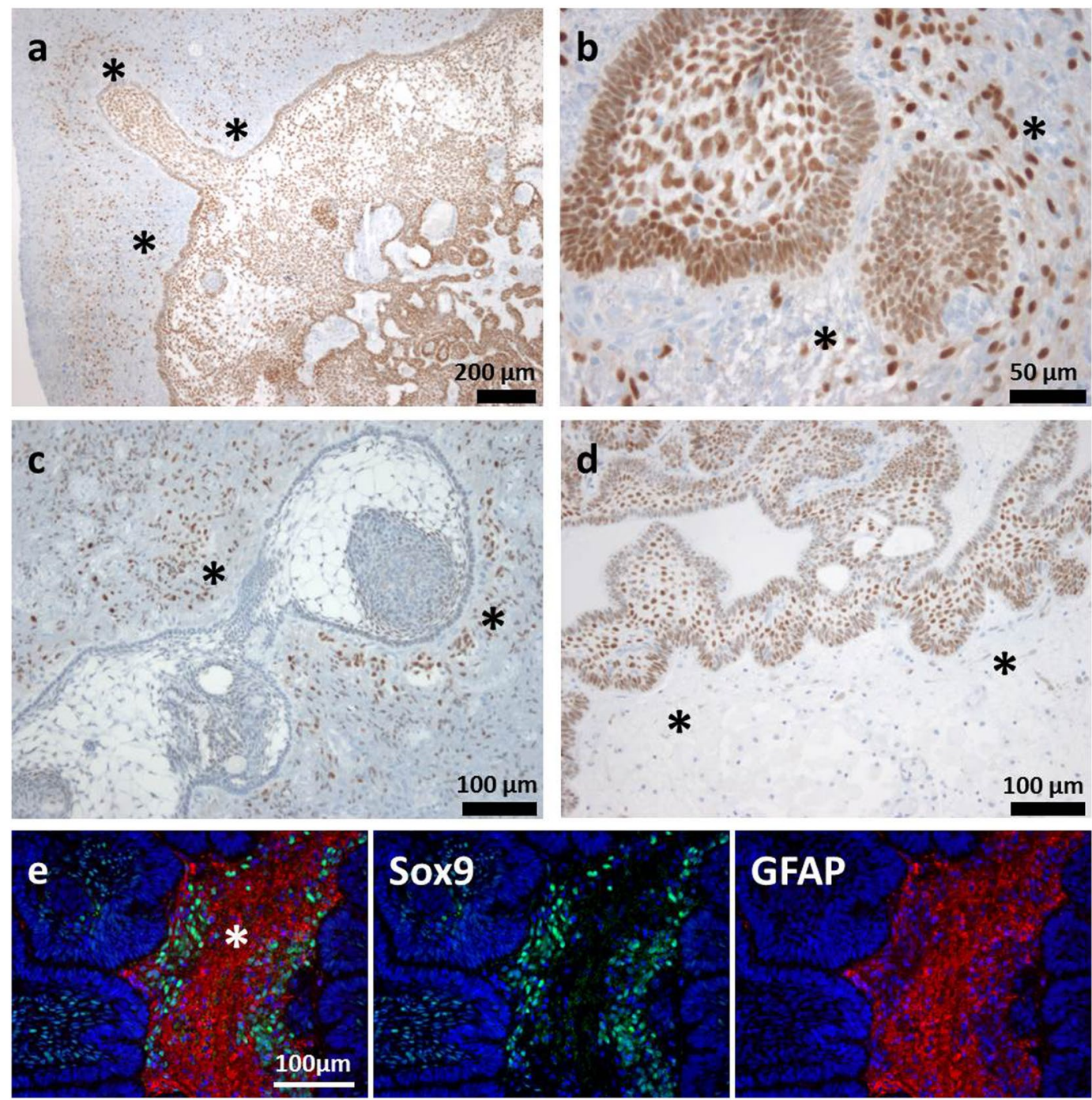

Figure 3. Varying Amounts of Sox 9 Expression in aCP and Surrounding Brain Tissue. (a,b) Some cases showed a higher level of nuclear Sox9 expression in both tumour and surrounding brain tissue indicated by an asterisk [ $\mathrm{a}=\operatorname{ada56}$ (TIS 12, BT 3), b = ada49 (TIS 12, BT 3)], whereas others (c,d) were predominantly stained in just one of the two. (c) ada28: Low Sox9 expression within the tumour tissue (TIS 3), distinct expression in the surrounding brain (BT 3). (d) ada27: High Sox9 expression scores within the tumour (TIS 12) and only occasional nuclear staining within the surrounding brain tissue (BT 1). (e) Merged double immunofluorescence staining of ada48 underscored enhanced levels of Sox9+ cells (green) within the tumour adjoining GFAP+ (red) brain tissue (asterisk). TIS = total immunostaining score, BT = staining score within tumour surrounding brain tissue.

surrounding brain tissue. Olig2 represents a transcription factor with important functions in the specification and differentiation of glial cells and neurons. Furthermore, Olig2 serves as a marker for progenitor cells and glioma stem cells (GSCs) and is required for glioma formation in a genetically relevant murine model ${ }^{42,53}$. Only recently, the existence of a new glial progenitor cell population was described, showing co-localization of Sox2 and Olig2 in the white matter of adult human brains. It was postulated that these cells may be responsible for tissue regeneration procedures $^{54}$. In the GFAP positive tumour surrounding brain parenchyma of aCP, several Sox $2+$ cells showed co-expression of Olig2. Whether these Sox $2+/$ Olig2 + cells represent de-differentiated astrocytes that acquire stem cell properties after injury ${ }^{51}$ or represent recruited progenitor cells from the perivascular niches and specific brain regions like the circumventricular organs ${ }^{55}$, remains unknown at this point. This important question and the function of Sox $2+/$ Olig $2+$ cells in the formation and maintenance of aCP must be studied in depth in the future.

With regard to $\mathrm{pCP}$, we could not detect any antigen reaction for Sox 2 in cells of the tumour surrounding $\mathrm{CNS}$ tissue. One reason for this could be the different growth behaviour of pCP compared to aCP with a lower potential for brain infiltration, slower tumour growth, and, therefore, reduced damage of brain parenchyma with less reactive processes. The missing activation of Wnt- and Shh- signalling pathways in pCP, most likely involved in the aforementioned processes, could be a further explanation for this interesting observation. 

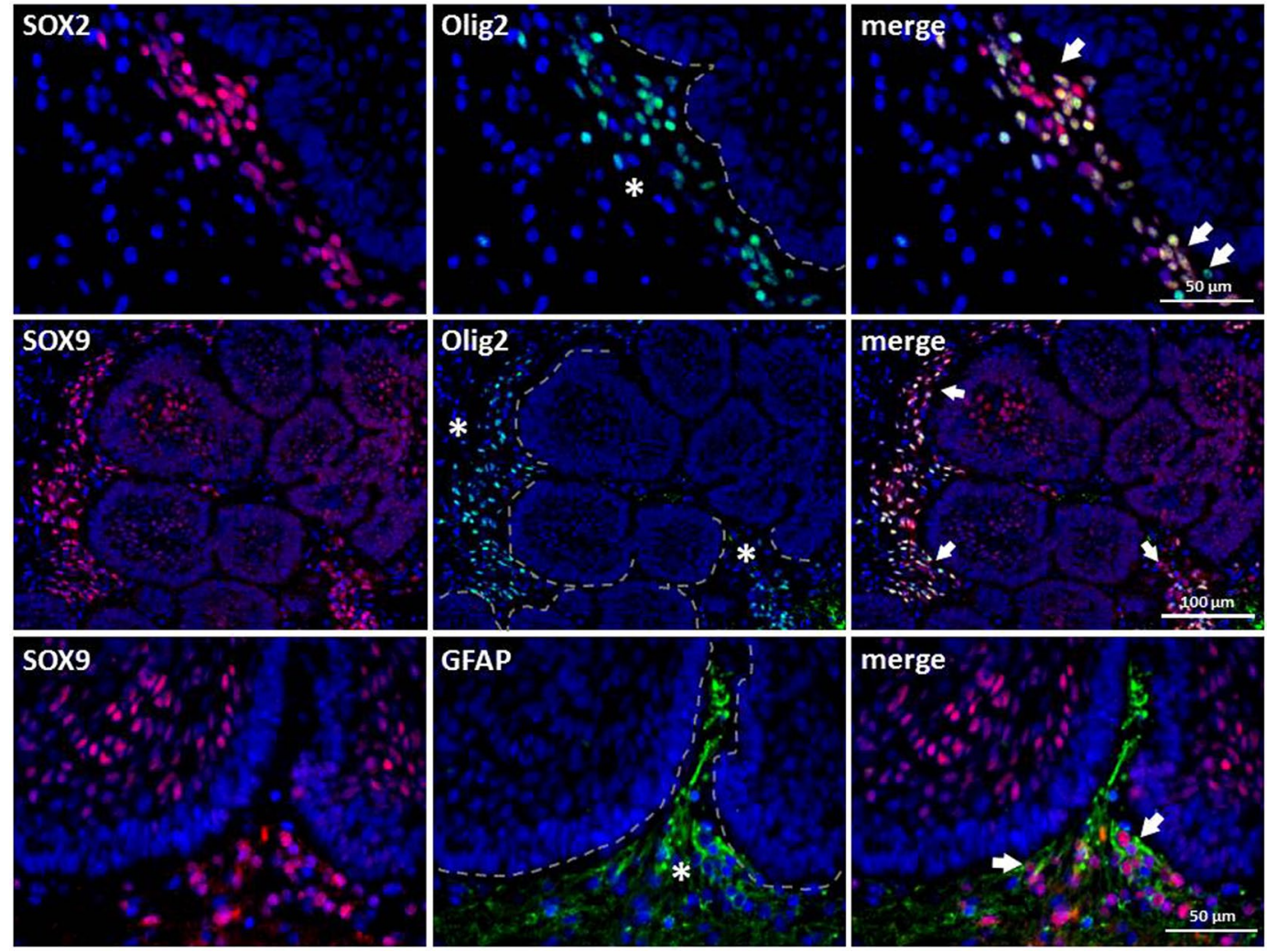

Figure 4. Co-expression of Sox 2 and Sox 9 with Olig2 in Cells of the Tumour Surrounding Brain Tissue. Double-immunofluorescence staining of ada48 showed that some but not all Sox $2+$ or Sox $9+$ cells (arrow) within the brain (asterisk) enclosing the tumour tissue (broken line) co-expressed Olig2. GFAP staining illustrates distinction between the epithelial tumour tissue (GFAP-) and adjacent brain tissue (GFAP+) with Sox9+ cells at the brain-tumour junction.

The SoxE-group member Sox9 fulfils important functions during chondrogenesis, testis formation, neural stem cell migration and the development of pancreas and intestine. Its physiological functions aside, Sox9 has also been shown in conjunction with acquired diseases like fibrosis and cancer ${ }^{40,56}$. The specific role of Sox 9 and its interaction with important signalling pathways have been best studied in chondrogenesis. Therefore, chondrocyte differentiation, proliferation, and maturation to hypertrophy are controlled by cross-talk between Sox 9 and the canonical Wnt signalling pathway ${ }^{33}$. In non-physiological conditions, previous studies revealed the regulatory role of Sox 9 on the transcription of Wnt genes in breast cancer cell ${ }^{57}$. Furthermore, it has previously been shown that overexpression of Sox 9 is associated with the activation of Wnt $/ \beta$-catenin signalling in brain tumours ${ }^{40}$. These facts are very interesting in relation to $\mathrm{CP}$ as $\beta$-catenin accumulating cells with subsequent Wnt signalling activation are the hallmark of aCP. In our study, it was precisely these cell-clusters which completely lacked Sox9 protein expression, while most of the surrounding tumour cells showed a strong antigen reaction. These results were consistent with those previously reported ${ }^{12}$.

This distribution pattern was significant in every single aCP specimen included in our study and confirms the results initially described in just a very small number of human tumour samples ${ }^{12}$. Using double-immunofluorescence staining and serial sections, this "punched-out" appearance in $\beta$-catenin accumulating cells became particularly obvious (Fig. 5) and indicates Sox9's possible role in regulating the cellular distribution pattern of $\beta$-catenin in aCP. Independent of its DNA binding ability, nuclear localization of Sox9 is described to be both sufficient and necessary to enhance $\beta$-catenin phosphorylation and its subsequent degradation ${ }^{41}$.

Sox 9 expression, in turn, has been described as being repressed by canonical Wnt/ $\beta$-catenin, respectively ${ }^{58-60}$. In this process, SOXC genes (Sox4, Sox 11 , and Sox12) elevate the $\beta$-catenin level and repress Sox9 in the perichondrium and joints. Furthermore, SOXC proteins are able to stabilize $\beta$-catenin by replacing Sox 9 and inhibiting GSK3 activity in the destruction complex ${ }^{61}$. It was already reported that Sox 9 regulates the balance between self-renewal and differentiation during tumorigenesis. The protein is required for basal cell carcinoma (BCC) formation regardless of the oncogenic stimuli, the cell of origin, and the body location from where the tumour arises. Furthermore, it is responsible for the long-term maintenance of oncogene-expressing cell $s^{62}$ and Sonic hedgehog (SHH), fibroblast growth factor (FGF-), and transforming growth factor $\beta$ (TGF- $\beta$ )/bone morphogenic protein (BMP)-family members have shown an increase of Sox9 expression in different developmental processes ${ }^{32,63}$.

The fact that mitogenic signals of SHH, FGF, and BMP have been shown to be secreted from isolated nuclear $\beta$-catenin accumulating cells in mice and human $\mathrm{aCP}^{46}$ indicates that there might be further paracrine interactions between the clusters and the surrounding Sox $9+$ cells. These are very interesting observations that could 

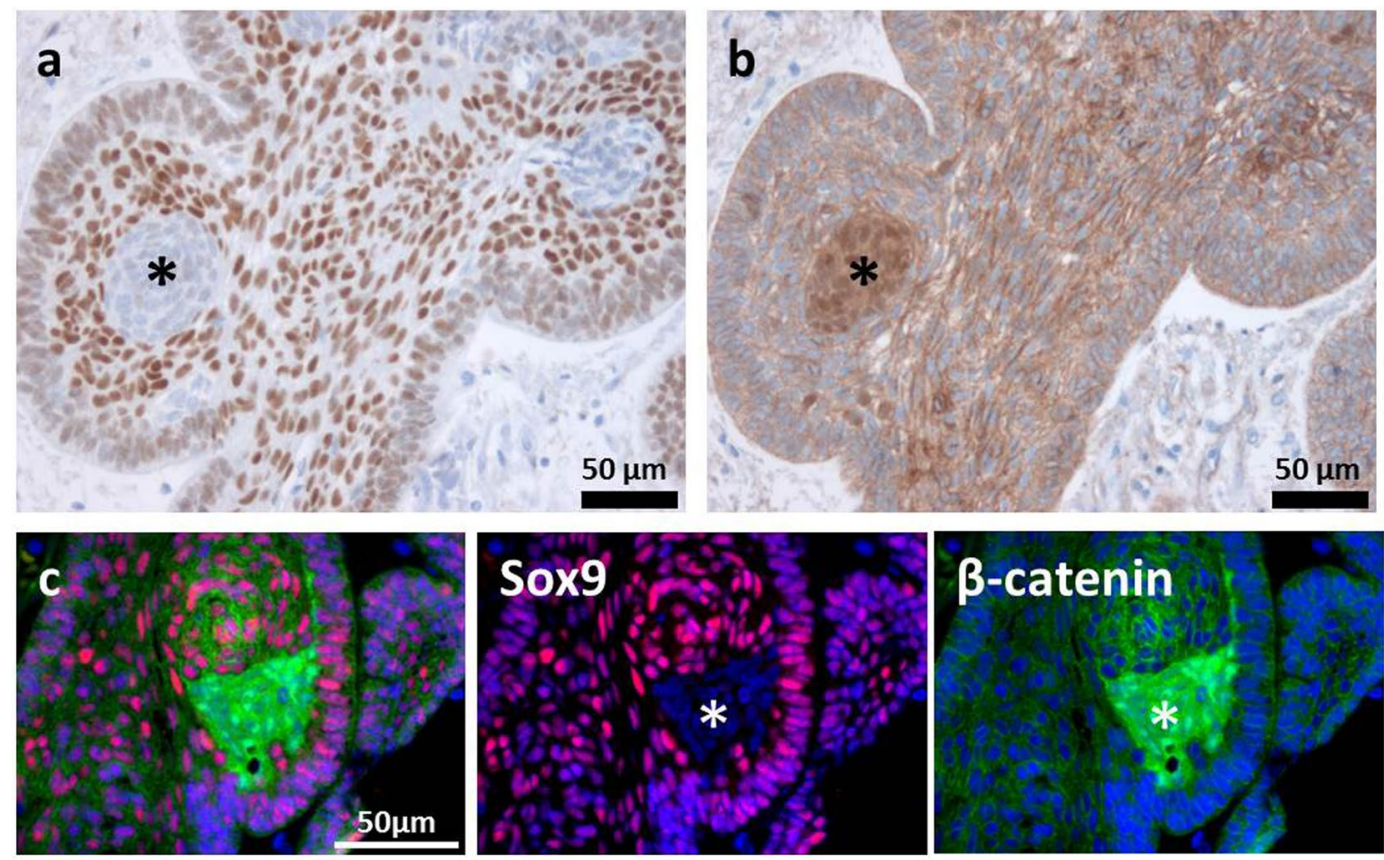

Figure 5. Correlation of Sox 9 and $\beta$-catenin Expression in Paraffin-embedded Serial Sections and Doubleimmunofluorescence Staining of aCP. Immunohistochemical staining of serial sections using antibodies against Sox9 (a) and $\beta$-catenin (b) showed the absence of Sox9 in cell clusters with nuclear $\beta$-catenin accumulations (*); Examples taken from ada47. Merging double-immunofluorescence staining with antibodies against Sox 9 and $\beta$-catenin (c), we were able to confirm the previous observation that cell clusters with nuclear $\beta$-catenin accumulations (green, asterisk) lack Sox9 expression (red, asterisk); Example was taken from ada50.

give further insights into the formation and maintenance of aCP and should be examined in more detail on the molecular level in the future.

Sox 9 , analogous to Sox2, has been previously reported as participating in reactive glial processes of the CNS. In this regard, a strong signal for Sox 9 could be proven in reactive gliosis in the cerebellum. In addition, SoxE-group members are further known to control different aspects of astrocyte and oligodendrocyte differentiation $^{63,64}$. Considering the antigen reaction of Sox 9 among the CP surrounding brain parenchyma, nearly all (98\%) of the aCP and $67 \%$ of the pCP samples revealed a specific staining. In contrast to Sox 2 , the Sox $9+$ cells were not concentrated next to certain areas of the tumour, but rather widely distributed among all the adjoining brain parenchyma. The Sox 9 antibody reaction was, however, stronger both in the aspect of quantity and as well as in the intensity in aCP compared to pCP. These differences, combined together with the fact that we were able to demonstrate Sox9+ cells, but no Sox 2 antigen reaction in the brain tissue around pCP, could be declared compatible with the varying growth behaviour of both tumour subtypes and a consequently different extent of reactive gliosis in the tumour surroundings. Our findings lead to the hypothesis that Sox $2+$ and Sox9+ cells may represent different cell types that are involved at temporally varying points of CNS tissue regeneration. This interesting speculation must be the subject of future investigations.

We additionally could prove a significant correlation between high amounts of Sox 9 and the appearance of Sox 2 positive cell clusters within the tumour surrounding brain tissue. This may reflect the theory that the extent of tumour growth behaviour affects reactive CNS processes and vice versa. Although an overexpression of Sox 9 has been associated with a poor clinical outcome of patients with malignant glioma ${ }^{65}$, comparing the protein and gene expression of both transcription factors with basic clinicopathological features (age groups, gender, and invasiveness) in CP patients showed no explicit association.

In summary, the stem cell transcription factors Sox 2 and Sox9 seem to play essential roles not only in the formation of $\mathrm{CP}$ but also in processes involving the tumour surrounding brain parenchyma. Particularly interesting is the inverse relation of Sox9 expression and activation of the Wnt- signalling pathway in aCP. Immunohistochemistry clearly demonstrates a possible impact of Sox9 in the cellular distribution pattern of $\beta$-catenin being essential for subsequent Wnt target gene activation. In the future, these relations have to be investigated on molecular level in more detail.

\section{Methods}

Patient Cohort. In terms of immunohistochemistry, we analysed surgical specimens from 73 patients with $\mathrm{CP}$, all of which were obtained as formalin fixed tissue from the archive of the Department of Neuropathology at the University Hospital Erlangen-Nürnberg. Appropriate surgeries have taken place in the Departments of Neurosurgery at the University Hospital Erlangen-Nürnberg, the International Neuroscience Institute in Hannover, the University Hospital Hamburg-Eppendorf, the Evangelic Hospital Bielefeld-Bethel, the University 
a

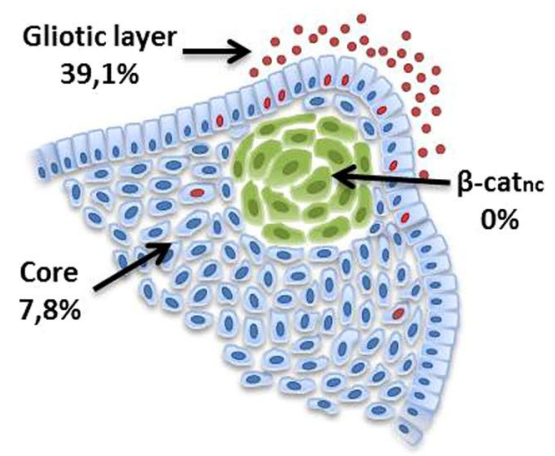

\section{Gliotic layer}

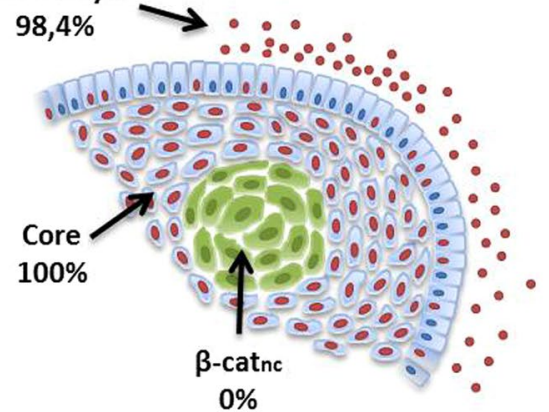

b

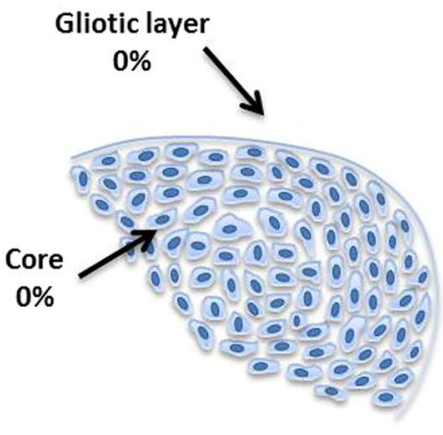

d

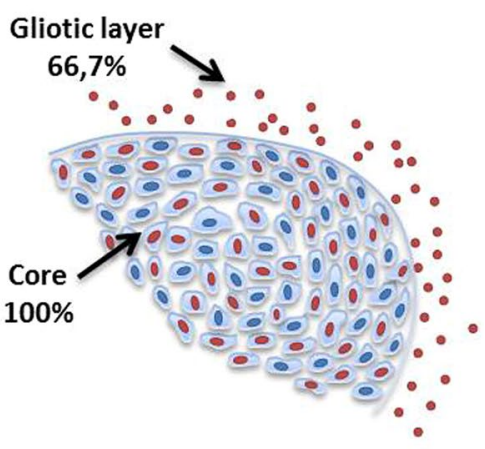

Figure 6. Percentage shares of Sox 2 and Sox 9 expression in aCP and pCP. Sox 2 expressing cells could be detected in only $7.8 \%$ of aCP and in $39.1 \%$ of the respective surrounding gliotic layer (a). In the latter Sox $2+$ cells appeared especially surrounding finger-like tumour protrusions $(\mathbf{a})$. pCP specimen appeared always negative (b). Sox 9 could be found in all tumour samples with showing a significantly stronger staining pattern in the core of aCP $(\mathbf{c})$ compared to $\mathrm{pCP}(\mathbf{d})(\mathrm{p}<0.0001)$. This was also true for the gliotic layer where $98.4 \%$ of aCP and $66.7 \%$ of pCP showed Sox9+ cells. Nuclear $\beta$-catenin accumulating cell clusters (green: $\beta$-cat ${ }_{\mathrm{nc}}$ ), exclusively found in aCP always remained negative both for Sox 2 and for Sox9.

General Hospital in Thessaloniki (Greece), the General Hospital in Vienna (Austria) and the Hospital "San Raffaele" in Milan (Italy). The group of CP contained 9 pCP and 64 aCP, representing a correct representation of the higher frequency of this CP subtype. Each tumour sample was classified according to World Health Organization guidelines and only specimens containing sufficient amounts of the respective CP subtype were taken into account. The clinical data and detailed information concerning each tumour sample are provided in Supplementary Table 1 (S-Table 1).

Ethical Approval and Informed Consent. All experimental protocols using human samples were approved by the Ethical Committee of the University of Erlangen-Nürnberg. Informed consent from all subjects was obtained. All used methods were carried out in accordance with the approved guidelines of the Ethical Committee of the University of Erlangen-Nürnberg and in accordance with the Declaration of Helsinki. A declaration of consent for further scientific investigation is available from each patient for all specimens as prescribed by the local ethics committee of the Friedrich-Alexander-University Erlangen-Nürnberg (FAU).

Immunohistochemistry. $\quad 3$ to $4 \mu \mathrm{m}$ thick sections of formalin-fixed and paraffin-embedded surgical samples were prepared, mounted on positively-charged object slides (Superfrost, Menzel, Braunschweig, Germany), and dried at $37^{\circ} \mathrm{C}$ overnight. Immunohistochemical staining was performed using a staining machine (Benchmark ULTRA IHC/ISH Staining Module; Ventana Roche; Illkirch, France) and the streptavidin-biotin-staining system Ventana DAB following the manufacturer's recommendations. Sox2 (SP76) was detected using a monoclonal rabbit-anti-Sox2 antibody (1:100; Cell Marque; Rocklin, CA, USA). A polyclonal rabbit-anti-Sox9 antibody (1:2500; Millipore; Temecula, CA, USA) was applied for visualization of Sox9. We utilised a monoclonal mouse-anti- $\beta$-catenin antibody (1:800; Clone 14; BD Biosciences; Franklin Lakes, NJ, USA) for detection of $\beta$-catenin. Olig2 expression was investigated using a monoclonal mouse-anti-Olig2-antibody (1:100; Clone 211F1.1; Millipore; Temecula, CA, USA). The staining procedures were verified by positive and negative controls (Sox2: squamous epithelium; Sox9: embryonic tissue; $\beta$-catenin: colon carcinoma; Olig2: normal brain, white matter).

Double Immunofluorescence Staining. Double immunofluorescence stainings were carried out manually on selected tumour specimens using antibodies against Sox 9 and $\beta$-catenin, Olig2 or GFAP (monoclonal mouse anti GFAP; 1:500; clone 6F2; Dako; Glostrup, Denmark) as well as Sox2 and Olig2 or GFAP. After 
dewaxing the slides, antigen retrieval by microwave pre-treatment was performed in citrate-buffer at $\mathrm{pH}$ 6. To prevent unspecific antibody binding, the slides then were incubated for two hours with a blocking solution containing PBS with foetal calf serum (5\%; Biochrom AG; Berlin, Germany), goat serum (3\%; Millipore; Temecula, CA, USA) and Triton $\times 100$ (0,1\%; Sigma-Aldrich; Steinheim, Germany). Primary antibodies were diluted in the blocking solution and incubated overnight at $4{ }^{\circ} \mathrm{C}$. Carbocyanine $2(\mathrm{Cy} 2)$ goat anti-mouse or goat anti-rabbit (1:100; green; Dianova; Hamburg, Germany) and Cy-3 goat anti-rabbit or goat anti-mouse secondary antibodies (1:100; red; Dianova; Hamburg, Germany) served as fluorescent markers, while cell nuclei were counterstained with Hoechst 33342 (Sigma Aldrich; Steinheim, Germany) at a concentration of $500 \mathrm{ng} / \mathrm{ml}$ for $5 \mathrm{~min}$ at room temperature. Slides were analysed using an Olympus BX-51 fluorescent microscope (Olympus; Hamburg, Germany) equipped with an F-View II CCD camera (Soft imaging systems; Stuttgart, Germany).

Immunohistochemical Scoring. Sox 2 and Sox 9 antigen expression was evaluated by three independent observers (VT, AH and RB) using light microscopy (Olympus BX-50, Model U-MDOB, Olympus, Tokyo, Japan). In cases of discordant results, the specimens were re-evaluated on a double-headed microscope to attain consensus. Antigen expression was assessed as positive if specific nuclear staining of tumour cells could be found. Only vital tumour areas and intact surrounding brain tissue were taken into account for both quantity and intensity assessments, whereas areas with pronounced inflammatory and/or regressive tissue changes were omitted.

The expression of Sox 9 was evaluated by calculating a total immunostaining score (TIS) following the assessment of quantity and intensity of the nuclear staining within the tumour as already described for other immunohistochemical markers ${ }^{66}$. A TIS is the product of a proportion score (PS), the estimated fraction of positive stained tumour cells $(0=0 \%, 1<10 \%, 2=10-50 \%, 3=50-80 \%, 4>80 \%)$, and an intensity score (IS). The IS defines the estimated staining intensity $(0=$ no staining at all; $1=$ weak staining; $2=$ moderate staining; $3=$ strong staining). The TIS ranges from 0 to 12 with only 9 possible values $(0,1,2,3,4,6,8,9,12)$. The Sox 9 total score was then divided into 3 scoring groups: scoring group 1 ( $\mathrm{S} 1$, no expression, TIS $=0)$ ), scoring group 2 (S2, low/ moderate expression, TIS $=1-4$ ) and scoring group 3 (S3, strong expression, TIS $>4$ ).

For Sox9, we additionally assessed the amount of nuclear antigen reaction in cells of the tumour surrounding brain tissue semi-quantitatively. To achieve an objective evaluation, we chose a similar score as previously described $^{49}$, taking 4 different scoring groups into account (BT 0-4): BT 0, no immunopositivity; BT 1, individual Sox9+ cells $(<10 \%)$; BT 2, moderate fraction of Sox9+ cells $(10-50 \%)$; BT 3, high fraction of Sox9+ cells (>50\%). S-Table 1 contains the respective scoring results of the tumour surrounding brain tissue for each sample.

With regard to Sox2, vital tumour areas and surrounding brain tissue were considered as well. As nuclear Sox2 staining within the tumour tissue could only be found in very rare cases, there was no need to create different quantity or intensity groups. This also applies for the environment, for which we only defined two distinct categories: "expression of Sox2" and "no expression of Sox2".

cDNA preparation. Total RNA of snap frozen tissue samples was isolated using TRIzol ${ }^{\circledR}$ Reagent (Invitrogen, Life Technologies) according to manufacturers' protocol or RNeasy ${ }^{\circledR}$ extraction kit (Qiagen, Hilden, Germany). From all specimens, frozen sections were microscopically reviewed to confirm tumour content. After digestion with RNase-free DNase I (Invitrogen, Life Technologies) total amount of RNA was determined by measuring probes on a NanoDrop (Thermo Fisher Scientific, Waltham, Massachusetts), followed by reverse transcription, using SuperScript First-strand synthesis system (Invitrogen, Life Technologies) with oligo (dT) primers. Due to limitations regarding the availability of frozen tumour sampels or tumour size and tumour content collectives of immunohistochemistry and mRNA are not absolutely congruent.

Quantitative Real Time PCR-Analysis. Relative quantification by qRT-PCR with Sybr Green II (Applied Biosystems, Life Technologies) was employed to assess the quantitative expression of Sox 2 and Sox9 in whole-tumour tissue of $7 \mathrm{pCP}$ and $26 \mathrm{aCP}$. To determine Sox expression relative quantification analyses were performed of CP cDNA. All analyses were carried out with the Applied Biosystems 7500 Fast Real-Time-PCR System (Applied Biosystems). Glyceraldehyde 3-phosphate dehydrogenase (GAPDH) was used as endogenous control of cDNA amount. Sequences of mRNA-specific primer employed in qRT-PCR analyses are listed in S-Table 2. To exclude nonspecific amplification, non-template controls for each primer were arranged on every plate and a melt curve analysis was performed. Analysis was conducted using the $\Delta \Delta \mathrm{C}_{\mathrm{T}}$-method according to manufacturers' instructions. The case pCP3 was used as calibrator. All analyses were carried out in triplicates and evaluated statistically using Graph Pad software Prism 7.00 (La Jolla, California).

Statistical Evaluation. In order to confirm the significance of differences in Sox9 protein expression between CP subgroups, Fisher's exact test was conducted to ensure reliable results amongst the relatively small number of samples. The same test was also used to analyse certain associations between different clinical characteristics (e.g. age group, gender or invasiveness) of the patient cohort and a high Sox9 expression in aCP. Those analyses were conducted using IBM SPSS Statistics 23 (IBM, Armonk, NY, USA). The results of gene expression were analysed for normal distribution employing the Kolmogorov-Smirnov and the Shapiro-Wilks test using Graph Pad software Prism 7.00 (La Jolla, California). As Gaussian distribution could not be assumed, a Mann-Whitney test was performed for further statistical evaluation regarding potential associations with clinicopathological features e.g. age group, gender or invasiveness.

\section{References}

1. D. N. Louis, H. Ohgaki, O. D. Wiestler \& W. K. Cavenee (eds.). WHO classification of tumours of the central nervous system (International Agency For Research On Cancer, Lyon, 2016).

2. Müller, H. L. Craniopharyngioma. Endocr Rev 35, 513-543 (2014). 
3. Karavitaki, N. et al. Craniopharyngiomas in children and adults. Systematic analysis of 121 cases with long-term follow-up. Clin Endocrinol 62, 397-409 (2005).

4. Hölsken, A. et al. Adamantinomatous and papillary craniopharyngiomas are characterized by distinct epigenomic as well as mutational and transcriptomic profiles. Acta Neuropathol Commun 4, 137 (2016).

5. Karavitaki, N. \& Wass, J. A. H. Craniopharyngiomas. Endocrinol Metab Clin North Am 37, 173 (2008).

6. Buslei, R. et al. Common mutations of $\beta$-catenin in adamantinomatous craniopharyngiomas but not in other tumours originating from the sellar region. Acta Neuropathol 109, 589-597 (2005).

7. Hölsken, A. et al. Target Gene Activation of the Wnt Signaling Pathway in Nuclear $\beta$-Catenin Accumulating Cells of Adamantinomatous Craniopharyngiomas. Brain Pathol 19, 357-364 (2009).

8. Sekine, S. et al. Craniopharyngiomas of Adamantinomatous Type Harbor $\beta$-Catenin Gene Mutations. Am J Pathol 161, 1997-2001 (2002).

9. Kato, K. et al. Possible linkage between specific histological structures and aberrant reactivation of the Wnt pathway in adamantinomatous craniopharyngioma. J Pathol 203, 814-821 (2004).

10. Liubinas, S. V., Munshey, A. S. \& Kaye, A. H. Management of recurrent craniopharyngioma. J Clin Neurosci 18, 451-457 (2011).

11. Garrè, M. L. \& Cama, A. Craniopharyngioma: modern concepts in pathogenesis and treatment. Curr Opin Pediatr 19, 471-479 (2007).

12. Gaston-Massuet, C. et al. Increased Wingless (Wnt) signaling in pituitary progenitor/stem cells gives rise to pituitary tumors in mice and humans. Proc Natl Acad Sci USA 108, 11482-11487 (2011).

13. Martinez-Barbera, J. P. \& Andoniadou, C. L. Concise Review: Paracrine Role of Stem Cells in Pituitary Tumors: A Focus on Adamantinomatous Craniopharyngioma. Stem Cells 34, 268-276 (2016).

14. Nguyen, L. V., Vanner, R., Dirks, P. \& Eaves, C. J. Cancer stem cells: an evolving concept. Nat Rev Cancer 12, 133-143 (2012).

15. Visvader, J. E. \& Lindeman, G. J. Cancer stem cells: current status and evolving complexities. Cell Stem Cell 10, 717-728 (2012).

16. Rosen, J. M. \& Jordan, C. T. The Increasing Complexity of the Cancer Stem Cell Paradigm. Science 324, 1670-1673 (2009).

17. Reya, T. \& Clevers, H. Wnt signalling in stem cells and cancer. Nature 434, 843-850 (2005).

18. Hölsken, A. et al. Adamantinomatous craniopharyngiomas express tumor stem cell markers in cells with activated Wnt signaling: further evidence for the existence of a tumor stem cell niche? Pituitary 17, 546-556 (2014).

19. Garcia-Lavandeira, M. et al. Craniopharyngiomas express embryonic stem cell markers (SOX2, OCT4, KLF4, and SOX9) as pituitary stem cells but do not coexpress RET/GFRA3 receptors. J Clin Endocrinol Metab 97, 7 (2012).

20. Wegner, M. From head to toes - the multiple facets of Sox proteins. Nucleic Acids Res 27, 1409-1420 (1999).

21. Wegner, M. \& Stolt, C. C. From stem cells to neurons and glia: a Soxist's view of neural development. Trends Neurosci 28, 583-588 (2005).

22. Arnold, K. et al. Sox2+ Adult Stem and Progenitor Cells Are Important for Tissue Regeneration and Survival of Mice. Cell Stem Cell 9, 317-329 (2011).

23. Alatzoglou, K. S., Kelberman, D. \& Dattani, M. T. The role of SOX proteins in normal pituitary development. J Endocrinol 200, $245-258$ (2009).

24. Fauquier, T., Rizzoti, K., Dattani, M. T., Lovell-Badge, R. \& Robinson Iain C. A. F. Sox2-expressing progenitor cells generate all of the major cell types in the adult mouse pituitary gland. Proc Natl Acad Sci USA 105, 2907-2912 (2008).

25. Kelberman, D. Mutations within Sox $2 / \mathrm{SOX} 2$ are associated with abnormalities in the hypothalamo-pituitary-gonadal axis in mice and humans. J Clin Invest (2006).

26. Weina, K. \& Utikal, J. SOX2 and cancer: current research and its implications in the clinic. Clin Transl Med 3, 19 (2014).

27. Hussenet, T. et al. SOX2 Is an Oncogene Activated by Recurrent 3q26.3 Amplifications in Human Lung Squamous Cell Carcinomas. PLoS ONE 5, e8960 (2010).

28. Annovazzi, L., Mellai, M., Calidera, V., Valente, G. \& Schiffer, D. SOX2 Expression and Amplification in Gliomas and Glioma Cell Lines. Cancer Genom Proteom 8, 139-148 (2011).

29. Andoniadou, C. L. et al. Sox $2(+)$ stem/progenitor cells in the adult mouse pituitary support organ homeostasis and have tumorinducing potential. Cell Stem Cell 13, 433-445 (2013).

30. Martinez-Barbera, J. P. \& Buslei, R. Adamantinomatous craniopharyngioma: pathology, molecular genetics and mouse models. J Pediatr Endocrinol Metabol 28, 7-17 (2015).

31. Bi, W., Deng, J. M., Zhang, Z., Behringer, R. R. \& Crombrugghe, Bde Sox9 is required for cartilage formation. Nat Genet 22, 85-89 (1999).

32. Kozhemyakina, E., Lassar, A. B. \& Zelzer, E. A pathway to bone: signaling molecules and transcription factors involved in chondrocyte development and maturation. Development 142, 817-831 (2015).

33. Akiyama, H. et al. Interactions between Sox 9 and B-catenin control chondrocyte differentiation. Genes Dev 18, 1072-1087 (2004).

34. Chaboissier, M.-C. Functional analysis of Sox8 and Sox9 during sex determination in the mouse. Development 131, 1891-1901 (2004).

35. Cheung, M. \& Briscoe, J. Neural crest development is regulated by the transcription factor Sox9. Development 130, 5681-5693 (2003).

36. Scott, C. E. et al. SOX9 induces and maintains neural stem cells. Nat Neurosci 13, 1181-1189 (2010).

37. Stolt, C. C. et al. The Sox9 transcription factor determines glial fate choice in the developing spinal chord. Genes Dev 17, 1677-1689 (2003).

38. Chang, C. V. et al. Differential Expression of Stem Cell Markers in Human Adamantinomatous Craniopharyngioma and Pituitary Adenoma. Neuroendocrinology 104, 183-193 (2017).

39. Scagliotti, V. et al. Histopathology and molecular characterisation of intrauterine-diagnosed congenital craniopharyngioma. Pituitary 19, 50-56 (2016).

40. Liu, H. et al. SOX9 Overexpression Promotes Glioma Metastasis via Wnt/3-Catenin Signaling. Cell Biochem Biophys (2015).

41. Topol, L., Chen, W., Song, H., Day, T. F. \& Yang, Y. Sox9 inhibits Wnt signaling by promoting beta-catenin phosphorylation in the nucleus. J Biol Chem 284, 3323-3333 (2009).

42. Trepant, A.-L. et al. Identification of OLIG2 as the most specific glioblastoma stem cell marker starting from comparative analysis of data from similar DNA chip microarray platforms. Tumour biology: the journal of the International Society for Oncodevelopmental Biology and Medicine 36, 1943-1953 (2015).

43. Barker, N. et al. Crypt stem cells as the cells-of-origin of intestinal cancer. Nature 457, 608-611 (2008)

44. Zhang, S. \& Cui, W. Sox2, a key factor in the regulation of pluripotency and neural differentiation. World J Stem Cells 6, 305-311 (2014).

45. Jayakody, S. A. et al. SOX2 regulates the hypothalamic-pituitary axis at multiple levels. J Clin Invest 122, 3635-3646 (2012).

46. Andoniadou, C. L. et al. Identification of novel pathways involved in the pathogenesis of human adamantinomatous craniopharyngioma. Acta Neuropathol 124, 259-271 (2012).

47. Ellis, P. et al. SOX2, a Persistent Marker for Multipotential Neural Stem Cells Derived from Embryonic Stem Cells, the Embryo or the Adult. Dev Neurosci 26, 148-165 (2004).

48. Liu, K. et al. The multiple roles for Sox2 in stem cell maintenance and tumorigenesis. Cellular signalling 25, 1264-1271 (2013).

49. Burghaus, S. et al. A tumor-specific cellular environment at the brain invasion border of adamantinomatous craniopharyngiomas. Virchows Arch 456, 287-300 (2010). 
50. Campbell, J. G., Miller, D. C., Cundiff, D. D., Feng, Q. \& Litofsky, N. S. Neural stem/progenitor cells react to non-glial cns neoplasms. Springerplus 4, 53 (2015).

51. Buffo, A. et al. Origin and progeny of reactive gliosis: A source of multipotent cells in the injured brain. Proc Natl Acad Sci USA 105, 3581-3586 (2008).

52. Magnus, T. et al. Evidence that nucleocytoplasmic Olig2 translocation mediates brain-injury-induced differentiation of glial precursors to astrocytes. J Neurosci Res 85, 2126-2137 (2007)

53. Ligon, K. L. et al. Olig2-regulated lineage-restricted pathway controls replication competence in neural stem cells and malignant glioma. Neuron 53, 503-517 (2007).

54. Oliver De La Cruz, Jorge et al. Sox2+ Cell Population from Normal Human Brain White Matter Is Able to Generate Mature Oligodendrocytes. PLoS ONE 9, e99253 (2014).

55. Bennett, L., Yang, M., Enikolopov, G. \& Iacovitti, L. Circumventricular organs: a novel site of neural stem cells in the adult brain. Mol Cell Neurosci 41, 337-347 (2009).

56. Pritchett, J., Athwal, V., Roberts, N., Hanley, N. A. \& Hanley, K. P. Understanding the role of SOX9 in acquired diseases: lessons from development. Trends Mol Med 17, 166-174 (2011).

57. Wang, H. et al. SOX9 regulates low density lipoprotein receptor-related protein 6 (LRP6) and T-cell factor 4 (TCF4) expression and Wnt/beta-catenin activation in breast cancer. The Journal of biological chemistry 288, 6478-6487 (2013).

58. Hill, T. P., Später, D., Taketo, M. M., Birchmeier, W. \& Hartmann, C. Canonical Wnt//-Catenin Signaling Prevents Osteoblasts from Differentiating into Chondrocytes. Dev Cell 8, 727-738 (2005).

59. Berge, D., ten, Brugmann, S. A., Helms, J. A. \& Nusse, R. Wnt and FGF signals interact to coordinate growth with cell fate specification during limb development. Development 135, 3247-3257 (2008).

60. Raspopovic, J., Marcon, L., Russo, L. \& Sharpe, J. Digit patterning is controlled by a Bmp-Sox9-Wnt Turing network modulated by morphogen gradients. Science 345, 566-570 (2014).

61. Bhattaram, P. et al. SOXC proteins amplify canonical WNT signaling to secure nonchondrocytic fates in skeletogenesis. J Cell Biol 207, 657-671 (2014).

62. Larsimont, J.-C. et al. Sox9 controls self-renewal of oncogene targeted cells and links tumor initiation and invasion. Cell Stem Cell $17,60-73(2015)$.

63. Jo, A. et al. The versatile functions of Sox9 in development, stem cells, and human diseases. Genes Dis 1, 149-161 (2014).

64. Kordes, U. \& Hagel, C. Expression of SOX9 and SOX10 in central neuroepithelial tumor. J Neurooncol 80, 151-155 (2006).

65. Wang, L. et al. Oncogenic role of SOX9 expression in human malignant glioma. Med Oncol 29, 3484-3490 (2012).

66. Thimsen, V. et al. EpCAM (CD326) is differentially expressed in craniopharyngioma subtypes and Rathke’s cleft cysts. Sci. Rep. 6, 29731 (2016)

\section{Acknowledgements}

We kindly thank Tajana Jungbauer, Diana Maron and Birte Rings for their expert technical assistance. We thank Beth Steger as native speaker for proofreading the manuscript. The present work was performed in fulfilment of the requirements for obtaining the degree "Dr. med." at the Friedrich-Alexander-Universität Erlangen-Nürnberg (FAU), Germany. We acknowledge support by the Deutsche Forschungsgemeinschaft and Friedrich-AlexanderUniversität Erlangen-Nürnberg (FAU) within the funding programme Open Access Publishing. This work was funded by the German Research Foundation DFG (NP-DFG_BU 2878/2-1).

\section{Author Contributions}

V.T. performed the experiments, evaluated the data, wrote the manuscript and prepared the figures. R.B. designed the experiments, evaluated the data and wrote the manuscript. A.H. conducted D.I.F. stainings for Olig2 and GFAP. N.J. performed and evaluated quantitative RT-PCR. M.B., R.F., J.F., H.S., E.K. and M.L. conducted surgery and provided tissue samples. All authors reviewed the manuscript.

\section{Additional Information}

Supplementary information accompanies this paper at https://doi.org/10.1038/s41598-017-15977-3.

Competing Interests: The authors declare that they have no competing interests.

Publisher's note: Springer Nature remains neutral with regard to jurisdictional claims in published maps and institutional affiliations.

(c) (i) Open Access This article is licensed under a Creative Commons Attribution 4.0 International Ly License, which permits use, sharing, adaptation, distribution and reproduction in any medium or format, as long as you give appropriate credit to the original author(s) and the source, provide a link to the Creative Commons license, and indicate if changes were made. The images or other third party material in this article are included in the article's Creative Commons license, unless indicated otherwise in a credit line to the material. If material is not included in the article's Creative Commons license and your intended use is not permitted by statutory regulation or exceeds the permitted use, you will need to obtain permission directly from the copyright holder. To view a copy of this license, visit http://creativecommons.org/licenses/by/4.0/.

(C) The Author(s) 2017 